
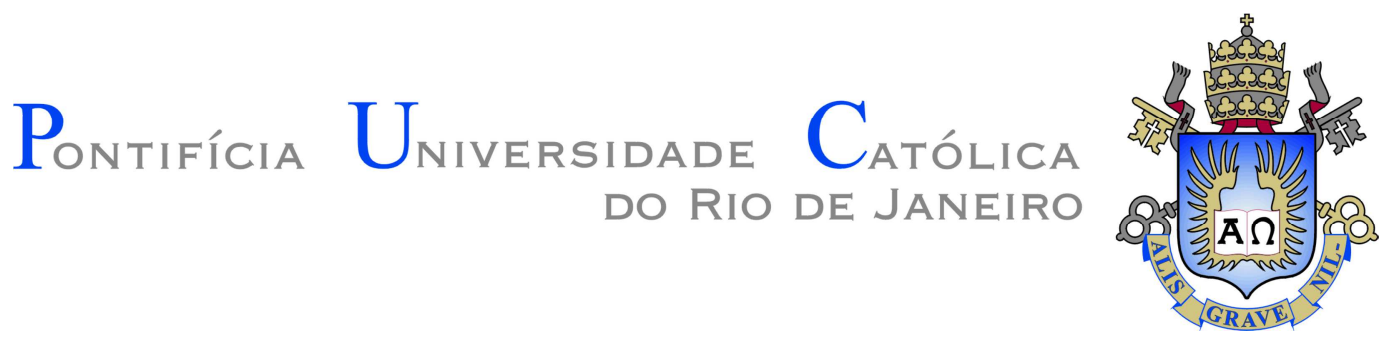

Jacqueline Lacerda Brito

\title{
Choque de Notícia Falsa - um caso de persistência do ruído no apreçamento de ativos
}

\section{Dissertação de Mestrado}

Dissertação apresentada como requisito parcial para obtenção de grau de Mestre pelo Programa de PósGraduação em Macroeconomia e Finanças do Departamento de Economia do Centro de Ciências Sociais da PUC-Rio.

Orientador: Prof. Ruy Monteiro Ribeiro

Rio de Janeiro

Julho de 2017 
Jacqueline Lacerda Brito

\author{
Choque de Notícia Falsa - um caso de \\ persistência do ruído no apreçamento de
}

ativos

Dissertação apresentada como requisito parcial para obtenção de grau de Mestre pelo Programa de PósGraduação em Macroeconomia e Finanças do Departamento de Economia do Centro de Ciências Sociais da PUC-Rio. Aprovado pela Comissão Examinadora abaixo assinada.

\author{
Prof. Ruy Monteiro Ribeiro \\ Orientador \\ Departamento de Economia - PUC-Rio
}

Prof. Marcelo Cunha Medeiros

Departamento de Economia - PUC-Rio

Axel André Simonsen

Vinci Partners

Profa. Mônica Herz

Coordenadora do Centro de Ciências Sociais - PUC-Rio

Rio de Janeiro, 03 de julho de 2017 
Todos os direitos reservados. É proibida a reprodução total ou parcial do trabalho sem autorização da universidade, da autora e do orientador.

Graduou-se em Economia pela Pontifícia Universidade Católica do Rio de Janeiro em 2009.

Ficha Catalográfica

Brito, Jacqueline Lacerda

Choque de notícia falsa : um caso de persistência do ruído no apreçamento de ativos / Jacqueline Lacerda Brito ; orientador: Ruy Monteiro Ribeiro. - 2017.

43 f. : il. color. ; $30 \mathrm{~cm}$

Dissertação (mestrado)-Pontifícia Universidade Católica do Rio de Janeiro, Departamento de Economia, 2017.

Inclui bibliografia

1. Economia - Teses. 2. Ruído. 3. Choque de notícia falsa. 4. Hipótese dos mercados eficientes. 5. Noise traders. 6. Apreçamento de ativos. I. Ribeiro, Ruy Monteiro. II. Pontifícia Universidade Católica do Rio de Janeiro. Departamento de Economia. III. Título. 


\section{Agradecimentos}

Agradeço ao meu orientador, Ruy Monteiro Ribeiro, pela parceria e aos amigos e familiares queridos por todo o apoio. 


\section{Resumo}

Brito, Jacqueline Lacerda; Ribeiro, Ruy Monteiro. Choque de Notícia Falsa - um caso de persistência do ruído no apreçamento de ativos. Rio de Janeiro, 2017. 43p. Dissertação de Mestrado - Departamento de Economia, Pontifícia Universidade Católica do Rio de Janeiro.

O presente trabalho busca analisar se um choque de notícia falsa que afetou os preços das ações da construtora europeia Vinci S.A., em novembro de 2016, teve algum componente de persistência na dissipação. Para tal, são construídos três modelos contrafactuais para traçar as trajetórias alternativas de preço que as ações da Vinci teriam percorrido na ausência do choque. A premissa básica do presente estudo é que os preços das ações são compostos por fundamento e por ruído (noise), sendo um choque de notícia falsa uma espécie de "fenômeno natural" em finanças, que torna possível separar o ruído dos fundamentos que definem o preço. Quando a informação falsa é absorvida como verdadeira, todos os agentes se tornam propagadores de ruído, ao passo que quando o ruído é revelado, o mercado deveria voltar a operar apenas com base nos fundamentos. Os resultados aqui encontrados apontam para uma rigidez temporária na trajetória de retorno do preço das ações ao seu preço fundamental após o choque, o que contraria a hipótese da incorporação imediata da informação ao preço proposta por algumas teorias de mercados eficientes. Os modelos aqui propostos mostraram-se bem especificados e as suas conclusões se corroboraram, conferindo robustez ao resultado.

\section{Palavras-chave}

Ruído; Choque de Notícia Falsa; Hipótese dos Mercados Eficientes; Noise Traders; Apreçamento de Ativos 


\section{Abstract}

Brito, Jacqueline Lacerda; Ribeiro, Ruy Monteiro (Advisor). Fake News Shock - a case of sticky noise in asset pricing. Rio de Janeiro, 2017. 43p. Dissertação de Mestrado - Departamento de Economia, Pontifícia Universidade Católica do Rio de Janeiro.

The present paper seeks to analyze if a fake news shock that affected the stock prices of the European construction company Vinci S.A., in November 2016, had any component of persistence in its dissipation. The paper constructs three contractual models to trace alternative trajectories for the price that Vinci stocks would have followed in the absence of the shock. The basic premise of this paper is that asset prices are composed both by noise and fundamental, and a fake news shock is a sort of "natural phenomena" in finance that makes it possible to identify the noise and the fundamental that compose prices. When false information is taken as true, all agents become temporally noise traders and when the noise is revealed, the market comes back to operate based on fundamental. The models point to a temporary stickiness of noise during the return of the prices to their fundamentals after the shock, contradicting the assumption of immediate incorporation of information to the price proposed by some Efficient Market Theories. The models have demonstrated to be well specified and they all have pointed to the same conclusions, conferring robustness to the results.

\section{Keywords}

Noise; False News Shock; Efficient Markets Hypothesis; Noise Traders; Asset Pricing. 


\section{Sumário}

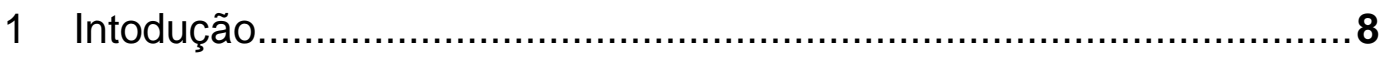

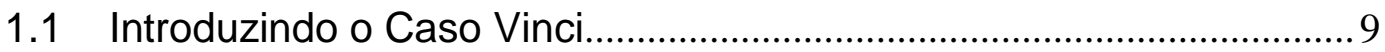

2 O Ruído na Literatura ..........................................................................11

3 Choques de Notícia Falsa na Literatura...................................................14

4 O Choque de Notícia Falsa - detalhando o caso Vinci ............................16

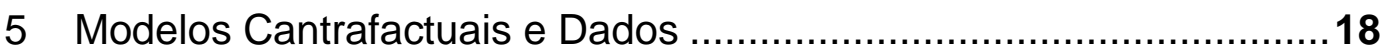

5.1 Modelo (1) - Fator de Mercado e Fator Setorial.................................... 19

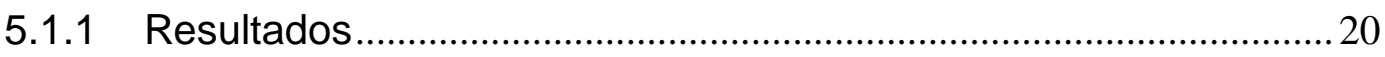

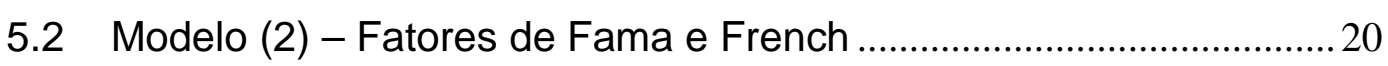

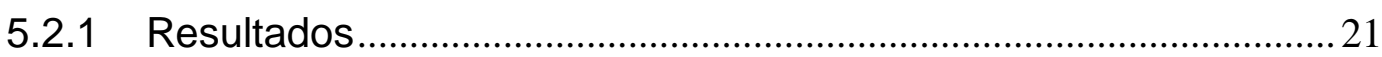

5.3 Modelo (3) - Fatores de Fama e French e Fator Setorial....................22

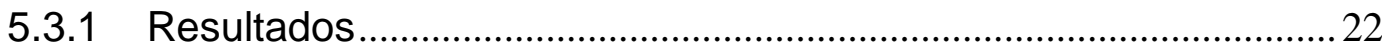

6 Estimando as Trajetórias de Preços para as Ações da Vinci .................24

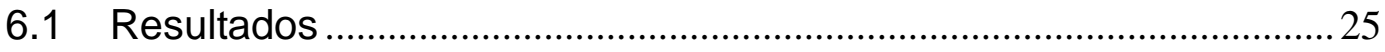

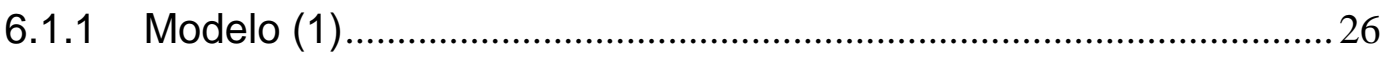

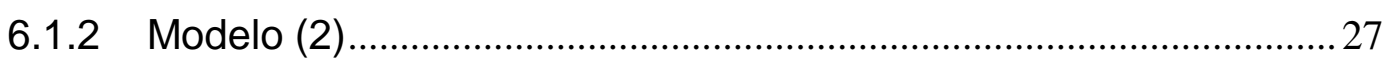

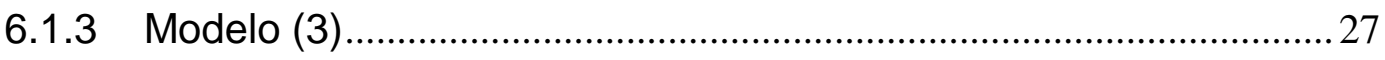

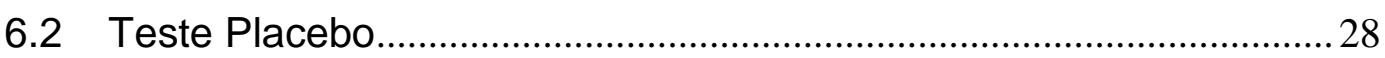

6.3 Teste de Robustez - Modelo de Frequência Diária................................32

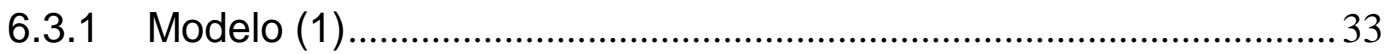

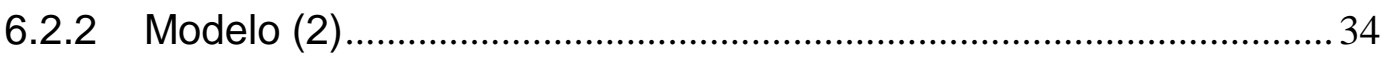

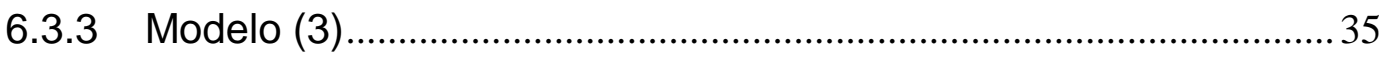

6.4 Buscando uma Alternativa para o Índice de Construção Civil ............36

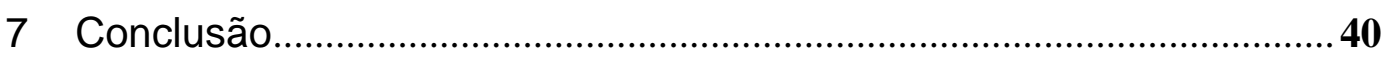

8 Referências bibliográficas ..................................................................... 42 


\section{Introdução}

No mercado financeiro, para que os arbitradores não realizem perdas advindas do desconhecimento de informação nova, há certa pressão para que eles respondam rapidamente ao que é veiculado pelas agências de notícia ou outros meios críveis de comunicação. A consequência disso é que, na presença de choques de notícias falsas - que nada mais são do que um ruído muito crível, mesmo aqueles agentes que costumam utilizar um framework racional para tomar as suas decisões podem ser levados a agir como propagadores de ruído.

Deste ponto de vista, os efeitos de notícias falsas sobre os preços dos ativos representam uma espécie de "fenômeno natural" em finanças, que leva todos os agentes a agirem temporariamente como noise traders: propagadores de ruído que distanciam o preço do ativo do seu fundamento, distorcendo o mercado.

Após a revelação de que a informação é inverídica, quando não se tem mais a totalidade dos investidores atuando como agentes propagadores de ruído, um choque exógeno e não-correlacionado com os fundamentos pode ser identificado, sendo possível fazer um esforço de segrega-lo dos demais fatores que determinam a variação do preço e inferir qual o efeito do ruído, uma vez revelado como tal, sobre os preços.

Em um estudo publicado pelo Journal of Empirical Finance, Carvalho et al. (2011) analisam as consequências de um emblemático choque provocado pela veiculação de um anúncio falso que reportava a falência da United Airlines. A notícia consistia na republicação em 2008 de uma matéria sobre um pedido de falência da Companhia que havia ocorrido em 2002. A notícia falsa levou a uma queda de até $76 \%$ do valor das ações da United Airlines. As ações se recuperaram ao longo do dia, mas tiveram um fechamento com queda de 11,2\%, mesmo após o esclarecimento de que a notícia em circulação pelo New York Times era falsa. Carvalho et al. (2011) exploram este experimento natural utilizando um modelo de precificação de ativos com bandas de desvio padrão, chegando à conclusão de que o choque provocado pela veiculação da notícia falsa teve efeito negativo 
persistente. Os autores, porém, não conseguem explicar as motivações para tal comportamento dos preços com base na literatura.

Utilizando como pano de fundo o framework teórico desenvolvido pela literatura de ruído sobre o apreçamento de ativos, este trabalho busca reproduzir o experimento de Carvalho et al. (2011) para um novo fenômeno natural que ocorreu no final de 2016, quando um choque de notícia falsa derrubou o valor das ações da construtora europeia Vinci S.A.

\section{1 \\ Introduzindo o Caso Vinci}

No final da tarde do dia 22 de novembro de 2016, um press-release publicado no site do Grupo francês Vinci S.A., um dos maiores da construção civil na Europa, anunciava que a Companhia faria uma revisão dos balanços contábeis de 2015 e do primeiro semestre de 2016. A revisão era motivada pelo resultado de uma auditoria interna, que teria identificado irregularidades que encobriam prejuízos nos últimos exercícios contábeis. O anúncio também informava que a Vinci havia demitido o seu CFO, Christian Labeyrie, e acionado o órgão regulador do mercado financeiro francês, a Autorité des Marchés Financiers, para tomar as medidas cabíveis. A notícia foi repercutida pelas agências de notícia, tendo sido publicada pela Bloomberg e pela Dow Jones. O anúncio foi seguido por uma queda de $19 \%$ do valor das ações da Vinci cotadas na Bolsa de Paris em um intervalo de 10 minutos, tendo o choque levado à interrupção das negociações do ativo.

A Companhia se manifestou logo em seguida, anunciando ter sido vítima de uma fraude, negando tanto a existência de irregularidades em seus últimos balanços quanto a demissão do seu CFO. A notícia falsa havia sido publicada em um domínio que parecia ser da Companhia, oferecendo e-mail e telefone de contato, todos falsos.

Após o anúncio de que a Vinci havia sido vítima de um ataque cibernético que havia implantado uma notícia falsa na mídia, as ações se recuperaram. Contudo, continuaram em declínio mesmo após o pronunciamento da Companhia 
e fecharam o dia $4 \%$ abaixo do valor de cotação imediatamente anterior à publicação da notícia falsa.

Considerando que os preços das ações são compostos por fundamento e por ruído, o presente trabalho utilizará o "experimento natural" da Vinci S.A. para tentar separar o ruído advindo de um choque de notícia falsa dos fundamentos que definem o preço. A premissa básica consiste no fato de que, quando a informação falsa é absorvida como verdadeira, todos os agentes se tornam propagadores de ruído ao passo que, quando o ruído é desmentido, o mercado volta a operar com base nos fundamentos.

O presente trabalho concluirá que houve inflexibilidade no retorno dos preços após o choque de notícia falsa no caso da Vinci, indicando que choques de ruído podem ter rigidez na dissipação. A presente dissertação está organizada da seguinte maneira: o Capítulo 2 consiste em uma revisão bibliográfica sobre os efeitos do ruído na literatura de apreçamento de ativos contrapondo as principais características da Hipótese dos Mercados Eficientes e da literatura de noise traders; o Capítulo 3 consiste em uma revisão bibliográfica sobre a literatura existente a respeito de choques oriundos de notícias falsas; o Capítulo 4 relata em detalhes o experimento natural da Vinci; o Capítulo 5 propõe 3 modelos empíricos para inferir os preços fundamentais das ações da Vinci após o choque de notícia falsa; o Capítulo 6 estima trajetórias de preços para as ações da Vinci baseadas nos modelos propostos no Capítulo 5 e realiza testes da robustez destes modelos e o Capítulo 7 apresenta a conclusão do experimento. 


\section{2 \\ O Ruído na Literatura - HME versus teorias de Noise Traders}

Em finanças, a literatura possui basicamente duas formas de abordar os efeitos do ruído sobre os preços: a Hipótese dos Mercados Eficientes e as teorias de noise traders.

A Hipótese dos Mercados Eficientes (HME) relaciona a trajetória dos preços dos ativos a um passeio aleatório ao qual todo fluxo de informação é imediatamente incorporado. A hipótese do passeio aleatório aniquila a possibilidade de se auferir ganhos de previsão sobre os preços dos ativos no longo prazo na medida os preços subsequentes consistem em desdobramentos aleatórios dos preços iniciais. A HME não nega o efeito de ruídos sobre os preços, mas postula que ou o seu valor médio é zero e seu efeito é não sistemático no longo prazo ou que na presença de efeitos sistemáticos do ruído sobre os preços não há limites à arbitragem.

A HME contrasta com modelos que consideram que os preços possam ser influenciados por fatores não relacionados aos fundamentos no longo prazo de forma sistemática: notadamente modelos que incorporam algum grau de irracionalidade dos agentes, como modelos da literatura de noise traders. Nesta literatura, o ruído (noise) representa um vetor que desloca os preços dos ativos dos seus fundamentos de maneira sistemática e limites à arbitragem são modelados de maneira a impedir um retorno à média dos preços. Em seu artigo seminal "Noise Trader Risk in Financial Markets" (1990) De Long, Shleifer, Summers e Waldmann constroem um modelo de gerações sobrepostas para descrever a presença de noise traders como introdutora de limites à arbitragem e de desvios dos preços dos ativos do seu fundamento, endossando que as variações nos preços dos ativos, mesmo no longo prazo, não podem ser descritas apenas na forma de variações nos fundamentos. Nas palavras de De Long et al. (1990): 
"Noise traders falsely believe that they have special information about the future price of the risky asset. They may get their pseudosignals from technical analysts, stockbrokers, or economic consultants and irrationally believe that these signals carry information. (...) Noise traders select their portfolios on the basis of such incorrect beliefs. In response to noise traders' actions, it is optimal for sophisticated investors to exploit noise traders' irrational misperceptions. Sophisticated traders buy when noise traders depress prices and sell when noise traders push prices up. Such active contrarian investment strategies push prices toward fundamentals, but not all the way."

De Long et al. (1990) propõem um modelo teórico para explicar os desvios dos preços dos ativos arriscados dos seus preços fundamentais com base na existência de investidores que agem com base em informação imperfeita, seja porque possuem um sistema irracional de formação de crenças seja porque usam fontes de informação sistematicamente errada. Neste modelo, agentes racionais e noise traders maximizam as suas funções utilidade dado o dividendo esperado a ser pago pelo ativo e a variância do preço, mas os noise traders consideram ainda a sua percepção/sentimento. O preço do ativo arriscado é derivado do modelo como uma função da percepção média dos noise traders e da sua percepção no futuro.

Os autores chegam à conclusão de que quanto maior o número de noise traders comparativamente ao de arbitradores racionais no mercado, maior o efeito do ruído sobre os preços e que a reversão à média dos preços dos ativos dependem do caráter temporário da percepção equivocada dos noise traders.

É esta incerteza a respeito de qual será o sentimento dos noise traders no futuro que introduz o risco de noise trader e reduz o preço do ativo. Quanto maior a proporção de noise traders, maior o impacto do ruído sobre o preço do ativo arriscado.

Portanto, enquanto os modelos que consideram algum grau de irracionalidade dos agentes buscam explicar como a incerteza quanto ao sentimento dos noise traders no futuro pode levar à permanência de desvios do preço fundamental dos ativos, modelos que se baseiam na HME defendem que os preços no longo prazo sempre irão convergir para os fundamentos, já que choques não correlacionados aos fundamentos são sempre não permanentes, seja pela ausência de limites à 
arbitragem, que empurra a média do ruído para zero, seja pela modelagem dos preços na forma de um passeio aleatório. 


\section{3 \\ Choques de Notícia Falsa na Literatura}

Entre os casos empíricos de choques de ruído analisados na literatura, o caso da United Airlines é sem dúvida um dos mais emblemáticos. Além de Carvalho et al. (2011), o caso da United Airlines já mereceu atenção de outros autores, como Lei (2009), que buscou evidenciar qual tipo de investidor responde mais fortemente ao choque que afetou a United e como se dá a sua resposta, e Marshall et al. (2009), que utilizaram o choque de notícia falsa da United Airlines como um evento para testar a hipótese da difusão gradual da informação e a hipótese de falta de atenção do investidor.

Na mesma linha de Carvalho et al. (2011) e do presente estudo, em 2001, Huberman e Regev analisaram um choque provocado por uma notícia de 1988, veiculada pelo New York Times, que tratava da descoberta de uma cura para o câncer pela farmacêutica EntreMed's. A divulgação da notícia pelo jornal de domingo levou a um aumento do preço das ações da Companhia de 7 vezes o seu valor após a abertura do pregão. A notícia, porém, não era nova e a informação já havia sido publicada há 5 meses na revista Nature e em outras mídias populares, incluindo o The Times. Apesar de não adicionar qualquer informação, após a divulgação da notícia pelo New York Times houve uma forte e persistente valorização das ações da EntreMed's, que se mantiveram em alta nas semanas seguintes, com spill-overs sobre as ações de outras companhias farmacêuticas. Os autores concluíram que o aumento permanente do preço se deveu em grande medida ao fator entusiasmo e não aos fundamentos.

Para investigar a reação do mercado de capitais a notícias que podem conter informação antiga ou defasada, Tetlock (2008) analisou notícias de jornal sobre o S\&P500, chegando à conclusão de que os agentes individuais reagem de maneira exagerada à informação antiga veiculada na mídia. Em artigo de 2008, Epstein e Schneider analisaram o efeito de informação ambígua sobre o apreçamento de ativos. Para tal, os autores construíram um modelo teórico 
segundo o qual os agentes são avessos à ambiguidade e na presença de informação imprecisa assumem o pior cenário, concluindo que choques na qualidade da informação podem ter efeitos negativos persistentes nos preços, mesmo que os fundamentos se mantenham inalterados.

A seguir, o presente trabalho descreve o caso da construtora Vinci S.A., que será analisado nos capítulos seguintes utilizando o mesmo ferramental proposto por Carvalho et al (2011). 


\section{4 \\ O Choque de Notícia Falsa - Detalhando o Caso Vinci}

No dia 22 de novembro de 2016, às 16:05 horas, horário de Paris, um pressrelease publicado no que parecia um endereço do site do Grupo francês Vinci, um dos maiores da construção civil na Europa, anunciava que o Grupo iria revisar os seus balanços de 2015 e da primeira metade de 2016 como resultado de uma auditoria interna que teria descoberto irregularidades nas demonstrações financeiras que estariam mascarando prejuízos nos últimos exercícios contábeis. $\mathrm{O}$ anúncio também informava que a Vinci havia demitido o seu CFO, Christian Labeyrie, e acionado o órgão regulador do mercado financeiro francês, a Autorité des Marchés Financiers, para tomar as medidas cabíveis. Nos dois minutos seguintes, o conteúdo do press-release foi veiculado pelas agências de notícias Dow Jones e Bloomberg.

Às 16:10 horas, um porta-voz da Vinci acionou as agências de notícias, alertando que o conteúdo divulgado às 16:05 era falso, negando tanto a existência de irregularidades em seus últimos balanços quanto a demissão do seu CFO. A notícia falsa havia sido divulgada em um site criado para parecer com o domínio da Companhia, mas com endereço, telefone e e-mail falsos.

Mesmo com o anúncio, às 16:15, a negociação das ações da Companhia na Bolsa de Paris - Euronext foi suspensa após uma queda de $19 \%$ do valor da cotação, que foi dos \$61,56 EUR (às 16:05) para uma mínima de \$49,93 EUR em um intervalo de menos de 10 minutos.

Poucos minutos depois, quando as negociações foram reiniciadas, o preço da ação começou a retornar para o seu nível de abertura e, às 16:49, com a cotação já em torno dos \$59 EUR, a Vinci emitiu um comunicado em seu site fazendo um novo alerta para a circulação da notícia com conteúdo falso. Às 17:02, em um novo movimento para dar transparência ao mercado, a Vinci encaminhou um anúncio por escrito ao órgão regulador, às agências de notícias e ao mercado financeiro negando a informação veiculada às 16:05. 
Apesar do esforço reiterado por parte da Vinci de desmentir o conteúdo falso divulgado no final da tarde da terça-feira e da ampla divulgação de que o Grupo não havia registrado prejuízos nem sido vítima de fraude no Balanço, o valor da ação da Companhia fechou o dia no nível de 58,80 EUR, 4\% abaixo do valor em vigor antes do anúncio da informação falsa. O que o presente experimento pretende evidenciar é se a persistência deste movimento de baixa ocorreu em função do choque de ruído ou por causas relacionadas aos fundamentos do preço da ação.

\section{Gráfico 1: VINCI S/A (€)}

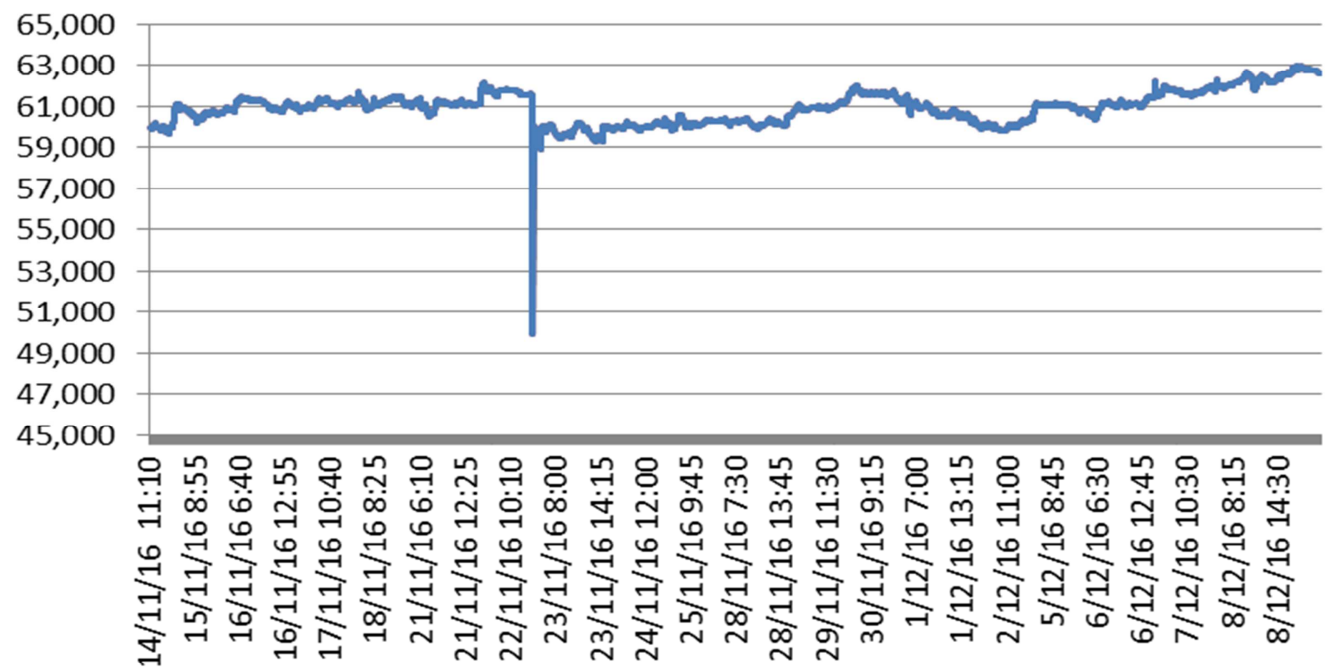




\section{5 \\ Modelos Contrafactuais e Dados}

No mercado financeiro, para auferirem ganhos, os arbitradores são pressionados a responder rapidamente ao que é veiculado pelas agências de notícia. Consequentemente, diante da veiculação de notícias falsas por fontes consideradas confiáveis, mesmo aqueles agentes que costumam utilizar um framework racional para tomar as suas decisões, podem ser levados a agir como noise traders: propagadores de ruído que distanciam o preço do ativo do seu fundamento, distorcendo o mercado. Um choque de notícia falsa consiste em puro ruído: a origem da variação dos preços não está correlacionada aos fundamentos do preço.

Após a revelação de que a informação é inverídica, quando não se tem mais a totalidade dos investidores atuando como agentes propagadores de ruído, um choque exógeno e não-correlacionado com os fundamentos pode ser identificado, sendo possível fazer um esforço de segrega-lo dos demais fatores que determinam a variação do preço e inferir qual o efeito do ruído, uma vez revelado como tal, sobre os preços.

Considerando que o choque de informação falsa se tratou apenas de ruído e que, portanto, tem correlação igual a zero com os fundamentos que afetam as ações da Vinci, este trabalho utiliza três modelos de fatores de apreçamento de ativos para testar se houve rigidez na dissipação dos efeitos do choque de notícia falsa.

Os três modelos consistem em 3 trajetórias contrafactuais para as ações da Vinci, ou seja, a trajetória que a ação teria percorrido na ausência da publicação falsa. Estas três possibilidades de caminhos para os preços das ações da Vinci na ausência do choque consistem em modelos de fatores lineares, com coeficientes calculados pelo Método de Mínimos Quadrados Ordinários. 


\section{1 Modelo (1) - Fator de Mercado e Fator Setorial}

Este modelo traça uma trajetória contrafactual para os retornos das ações da Vinci em função da sua correlação com o mercado e com a performance setorial global da construção civil. O retorno da Vinci é estimado em função de dois fatores: os retornos em excesso do mercado (representado pelo EuroStoxx Index) e os retornos em excesso da construção civil (representados pelo Stoxx Global 1800 Construction and Materials EUR Price Index). EuroStoxx Index é composto por uma combinação de pequenas, médias e grandes empresas das maiores economias da Zona Euro e a Vinci representa apenas $1 \%$ da composição deste índice, tornando-o um bom índice representativo do mercado para o experimento. O Stoxx Global 1800 Construction and Materials EUR Price Index é um índice setorial global para o setor da Construção Civil e Materiais e a participação da Vinci na composição do índice é de 10\%. A participação é elevada e pode levar a problemas de endogeneidade nos experimentos, porém, a utilização de um índice global mostrou-se mais adequada do que a utilização de índices para a Europa, que teriam ainda mais peso da Vinci na sua composição.

Para a construção da trajetória contrafactual, foram estimados coeficientes para as variáveis com base em dados de 14:25 de 12 de outubro de 2016 até o momento imediatamente anterior à divulgação da informação falsa, em 16:05 de 22 de novembro de 2016. Os dados possuem frequência de 5 minutos, consistem em valores de fechamento e foram retirados da Thompson Reuters. Com a exceção da taxa livre de risco, que foi retirada da Bloomberg com frequência diária e supondo-se valores diários fixos.

A seguir, o modelo fatorial estimado através do Método dos Mínimos Quadrados Ordinários:

$$
\text { (1) }\left(r_{V, t}-r_{t}\right)=\alpha+\beta_{M}\left(\mathrm{r}_{M, t}-r_{t}\right)+\beta_{C V}\left(r_{C V, t}-r_{t}\right)
$$

As siglas $r_{V, t}, \quad \mathrm{r}_{M, t} \mathrm{e} \quad r_{C V, t}$ representam, respectivamente, os retornos logarítmicos entre t e t-1 das ações da Vinci, do mercado e da construção civil. A $r_{t}$ representa a taxa livre de risco, aproximada pelo rendimento do título de 10 anos do Governo da Alemanha. 


\section{1 .1 Resultados}

O Modelo contrafactual (1) apresenta resultados bastante consistentes: um R-Quadrado elevado $(0,5)$, ou seja, forte poder explicativo da variação do preço das ações da Vinci, os sinais economicamente esperados para as variáveis explicativas (>0), já que a Vinci é uma empresa que depende positivamente da performance da construção civil, e significância estatística para os coeficientes dos dois fatores. Além disso, foram realizadas regressões para amostras de períodos menores (menos observações), que demonstraram uma relativa estabilidade dos betas em termos de sinais e magnitudes. A seguir, os resultados da estimação do modelo com fator de mercado e fator setorial:

\begin{tabular}{cc}
\multicolumn{3}{c}{ Tabela 1: Resumo dos Resultados do Modelo 1 } \\
\hline Parâmetros & Estimativas \\
\hline \hline$\widehat{\alpha}$ & $-2,91 \mathrm{E}-05$ \\
$\widehat{\beta}_{M}$ & {$[0,12]$} \\
& $4,21 \mathrm{E}-01$ \\
$\widehat{\beta}_{C V}$ & $(0,00)$ \\
& $6,99 \mathrm{E}-01$ \\
$\mathrm{R}^{2}$ & $(0,00)$ \\
$\#$ Obs & 0,50 \\
$\hat{\sigma}_{\theta}$ & 2.953 \\
\hline \hline
\end{tabular}

\section{2 \\ Modelo (2) - Fatores de Fama e French}

O segundo modelo utilizado para traçar um contrafactual para a trajetória das ações da Vinci consiste em uma adaptação do reconhecido modelo de Fama e French. Os retornos logarítmicos das ações da Vinci foram estimados em função do retorno em excesso do mercado, de um fator que consiste na diferença entre os retornos logarítmicos das ações de empresas com alta razão entre valor contábil/valor de mercado e empresas com baixo valor para a razão valor contábil/valor de mercado e, por fim, de um fator que consiste na diferença entre os retornos logarítmicos das ações das empresas de baixa capitalização e das ações das empresas de alta capitalização. 
Para construir o modelo, buscaram-se proxies para os fatores de Fama e French através da utilização de índices de mercado. O retorno representativo das ações de empresas de alto valor contábil/valor de mercado, $r_{H, t}$, foi aproximado pelo Euro Stoxx Total Market Value EUR Price Index, o retorno das ações de empresas de baixo valor contábil/valor de mercado, $r_{L, t}$, foi aproximado pelo Euro Stoxx Total Market Growth EUR Price Index, o retorno das ações de empresas de baixa capitalização, $r_{S, t}$, foi aproximado pelo Euro Stoxx Small EUR Price Index e o retorno das ações de empresas muito capitalizadas, $r_{B, t}$, foi representado pelo Euro Stoxx Large EUR Price Index. Assim como no caso anterior, os dados são valores de fechamento com frequência de 5 minutos retirados da Thompson Reuters e possuem o time frame até o momento imediatamente anterior à divulgação da informação falsa. Todos os índices são representativos de empresas da Zona Euro e possuem uma participação da Vinci na composição inferior a $2 \%$.

A seguir, o segundo modelo fatorial estimado através do Método dos Mínimos Quadrados Ordinários:

(2) $\left(r_{V, t}-r_{t}\right)=\alpha+\beta_{M}\left(\mathrm{r}_{M, t}-r_{t}\right)+\beta_{S M B}\left(r_{S, t}-r_{B, t}\right)+\beta_{H M L}\left(r_{H, t}-r_{L, t}\right)$

\subsection{1}

\section{Resultados}

O modelo contrafactual (2) também apresenta resultados consistentes: um R-Quadrado elevado $(0,5)$, os sinais esperados para as variáveis explicativas, já que a Vinci é uma empresa grande e pode ser classificada como "growth" por causa do seu elevado valor de mercado, e significância estatística para os coeficientes dos fatores de Fama e French. Além disso, também foram realizadas regressões para amostras de períodos menores, que demonstraram uma relativa estabilidade dos betas em termos de sinais e magnitudes. A seguir, os resultados da estimação do modelo com fatores de Fama French: 


\begin{tabular}{cc}
\multicolumn{2}{c}{ Tabela 2: Resumo dos Resultados do Modelo 2 } \\
\hline \hline Parâmetros & Estimativas \\
\hline \hline$\widehat{\alpha}$ & $-1,18 \mathrm{E}-05$ \\
$\widehat{\beta}_{M}$ & $(0,54)$ \\
& 1,05 \\
$\widehat{\beta}_{S M B}$ & $(0,00)$ \\
$\widehat{\beta}_{H M L}$ & $-0,09$ \\
& $(0,00)$ \\
$\mathrm{R}^{2}$ & $-0,47$ \\
$\#$ Obs & $(0,01)$ \\
$\hat{\sigma}_{\theta}$ & 0,47 \\
\hline \hline
\end{tabular}

\section{3 \\ Modelo (3) - Fatores de Fama e French e Fator Setorial}

O terceiro modelo construído para estimar a trajetória contrafactual das ações da Vinci consiste em uma composição dos outros dois modelos, incluindo tanto os fatores de Fama e French quanto o fator setorial da Construção Civil, conforme modelo a seguir:

(3) $\left(r_{V, t}-r_{t}\right)=$

$$
\alpha+\beta_{M}\left(r_{M, t}-r_{t}\right)+\beta_{S M B}\left(r_{S, t}-r_{B, t}\right)+\beta_{H M L}\left(r_{H, t}-r_{L, t}\right)+\beta_{C V}\left(r_{C V, t}-r_{t}\right)
$$

Assim como nos casos anteriores, os dados são valores de fechamento com frequência de 5 minutos retirados da Thompson Reuters e possuem o time frame até o momento imediatamente anterior à divulgação da informação falsa.

\subsection{1}

\section{Resultados}

O modelo contrafactual (3) apresenta os mesmos resultados consistentes verificados nos modelos (1) e (2): um R-Quadrado elevado $(0,5)$, os sinais esperados para as variáveis explicativas, dependendo positivamente da construção civil e negativamente dos fatores de Fama e French, tal como no modelo anterior, e significância estatística tanto para os coeficientes dos fatores de Fama e French quanto para o fator setorial. Além disso, também foram realizadas regressões para amostras de períodos menores, que demonstraram uma relativa estabilidade dos 
betas. A seguir, os resultados da estimação do modelo com fatores de Fama e French e com o controle de fator setorial:

\begin{tabular}{cc}
\multicolumn{2}{c}{ Tabela 3: Resumo dos Resultados do Modelo 3} \\
\hline \multicolumn{1}{c}{ Parâmetros } & Estimativas \\
\hline \hline$\widehat{\alpha}$ & $-2,32 \mathrm{E}-05$ \\
& $(0,20)$ \\
$\widehat{\beta}_{M}$ & $4,93 \mathrm{E}-01$ \\
& $(0,00)$ \\
$\widehat{\beta}_{C V}$ & $6,75 \mathrm{E}-01$ \\
$\widehat{\beta}_{S M B}$ & $(0,00)$ \\
$\widehat{\beta}_{H M L}$ & $-1,98 \mathrm{E}-01$ \\
& $(0,00)$ \\
& $-4,06 \mathrm{E}-01$ \\
$\mathrm{R}^{2}$ & $(0,00)$ \\
$\#$ Obs & 0,52 \\
$\hat{\sigma}_{\theta}$ & 2,953 \\
\hline \hline
\end{tabular}

É importante destacar que, para todos os modelos contrafactuais, não se identificou uma variável explicativa exógena para a construção civil como Carvalho et al. (2011) identificaram para o seu caso de estudo para o setor aéreo americano na forma do preço do petróleo, o que pode ter implicações em termos de alguma endogeneidade para os modelos apresentados. Destaca-se ainda que a análise dos dados também não identificou uma variação significativa na liquidez dos preços das ações da Vinci, tal como investigado por Carvalho et al. (2011). 


\section{6 Estimando as Trajetórias de Preços para as Ações da Vinci}

Uma vez definidos os modelos para construção dos contrafactuais, é possível utilizar os coeficientes obtidos para estimar as trajetórias alternativas para o preço das ações da Vinci na ausência do choque de notícia falsa, utilizando as seguintes equações para cada um dos modelos propostos para o período imediatamente após o choque:

$$
\begin{gathered}
\text { (1) } \begin{aligned}
& \hat{r}_{V, t}=\widehat{\alpha}+ r_{t}+\hat{\beta}_{M}\left(\mathrm{r}_{M, t}-r_{t}\right)+\hat{\beta}_{C V}\left(r_{C V, t}-r_{t}\right) ; \mathrm{t}>\mathrm{t}_{0} \\
& \text { (2) } \hat{r}_{V, t}=\widehat{\alpha}+ r_{t}+\widehat{\beta}_{M}\left(\mathrm{r}_{M, t}-r_{t}\right)+\widehat{\beta}_{S M B}\left(r_{S, t}-r_{B, t}\right) \\
&+\hat{\beta}_{H M L}\left(r_{H, t}-r_{L, t}\right) ; \mathrm{t}>\mathrm{t}_{0} \\
& \text { (3) } \hat{r}_{V, t}=\hat{\alpha}+r_{t}+\hat{\beta}_{M}\left(\mathrm{r}_{M, t}-r_{t}\right)+\hat{\beta}_{S M B}\left(r_{S, t}-r_{B, t}\right)+\hat{\beta}_{H M L}\left(r_{H, t}-r_{L, t}\right) \\
&+\hat{\beta}_{C V}\left(r_{C V, t}-r_{t}\right) ; \mathrm{t}>\mathrm{t}_{0}
\end{aligned}
\end{gathered}
$$

Os betas com circunflexo representam os coeficientes estimados pelos modelos contrafactuais e os valores sem circunflexo à direita das equações representam os valores reais dos fundamentos escolhidos para estimar os modelos. A partir destes valores, podemos estimar $\hat{r}_{V, t}$ (retorno das ações da Vinci) período a período para cada um dos modelos.

Partindo do valor da ação da Vinci no momento imediatamente anterior à divulgação da notícia falsa (16:05, 22 de novembro), quando a cotação estava em 61,56 EUR, pode-se calcular a trajetória de preço transformando este último preço em logaritmo e adicionando-o às variações logarítmicas estimadas na forma dos $\hat{r}_{V, t}$. Na sequência, aplicando-se uma transformação exponencial nestes valores, obtém-se uma estimativa de preço para cada período. 


$$
\hat{p}_{V, t}=p_{V, t_{0}-1}+\sum_{j=t_{0}}^{t} \hat{r}_{V, t}, t \geq t_{0}
$$

Para considerar desvios do modelo, tal como Carvalho et al. (2011), foram adicionados intervalos de confiança utilizando o erro padrão de cada um dos modelos de mínimos quadrados ordinários estimados, onde $\mathrm{t}_{0}$ é o momento do choque e $\mathrm{t}>\mathrm{t}_{0}$ são os períodos imediatamente após o choque.

$$
\hat{p}_{V, t} \pm \sqrt{t-\left(t_{0}-1\right) \hat{\sigma}_{e}}
$$

\section{1}

\section{Resultados}

Considerando contrafactuais estimados, comparamos as trajetórias projetadas pelos 3 modelos com a trajetória real da ação após o choque de notícia falsa. Para analisar a durabilidade do choque, foi feita uma comparação do valor real da ação com aquele estimado pela banda inferior dos intervalos de confiança construídos, identificando em que momento o valor da ação ultrapassa este limite, retornando ao intervalo de confiança estimado.

Considerando os modelos propostos, conclui-se que em nenhum deles o choque é dissipado após a reabertura das negociações. Dado que a divulgação da notícia falsa ocorreu no dia 22 de dezembro às 16:05 horas, que às 16:10 horas a Vinci alertou as agências de notícias a respeito e que às 16:15 horas a negociação das ações da Companhia na Bolsa de Paris foi suspensa, pode-se supor que a informação de que a notícia era falsa havia sido amplamente divulgada até as 16:15 horas, ou seja, às 16:15 o choque deveria ter sido anulado.

Porém, em todos os modelos, o choque leva pelo menos dois dias para se dissipar. No modelo (1), com fatores de mercado e setorial, o preço atravessa a banda inferior do intervalo de confiança previsto a partir das 12:20 do dia 24 de novembro (2 dias depois); no modelo (2), com fatores de Fama e French, o preço ingressa no intervalo previsto a partir das 11:05 do dia 25 de novembro (3 dias depois) e no modelo (3), com fatores de Fama e French e com fator setorial, o preço atravessa a banda inferior do intervalo de confiança a partir das 09:05 do dia 25 de novembro (3 dias depois), o que leva à conclusão de que o choque foi 
dissipado, mas houve rigidez no retorno da ação ao seu valor fundamental tal como definido pelos modelos aqui propostos.

A seguir, são demostradas graficamente as estimativas contrafactuais resultantes dos modelos (1), (2) e (3) para os preços das ações da Vinci em um período de 20 dias após o choque (até 12 de dezembro de 2016).

\subsection{1 \\ Modelo (1)}

Considerando o contrafactual estimado a partir de fatores de mercado e da construção civil, verificamos que o modelo descreve bem o movimento do preço da ação até a metade do período projetado, após o qual parece subestimá-la, uma vez que o preço real do ativo parece coincidir com a banda superior do intervalo de confiança. Tal fato, porém, não impacta a conclusão do modelo de que parece haver rigidez na volta do valor da ação da Vinci ao seu valor fundamental, pois se o modelo subestima o valor da ação, este fato propiciaria uma entrada mais rápida no intervalo de confiança após o choque. O gráfico a seguir, assim como os demais, começa no instante imediatamente anterior ao choque, às 16:05 horas do 22 de novembro - horário de Paris, quando a ação valia 61,56 EUR.

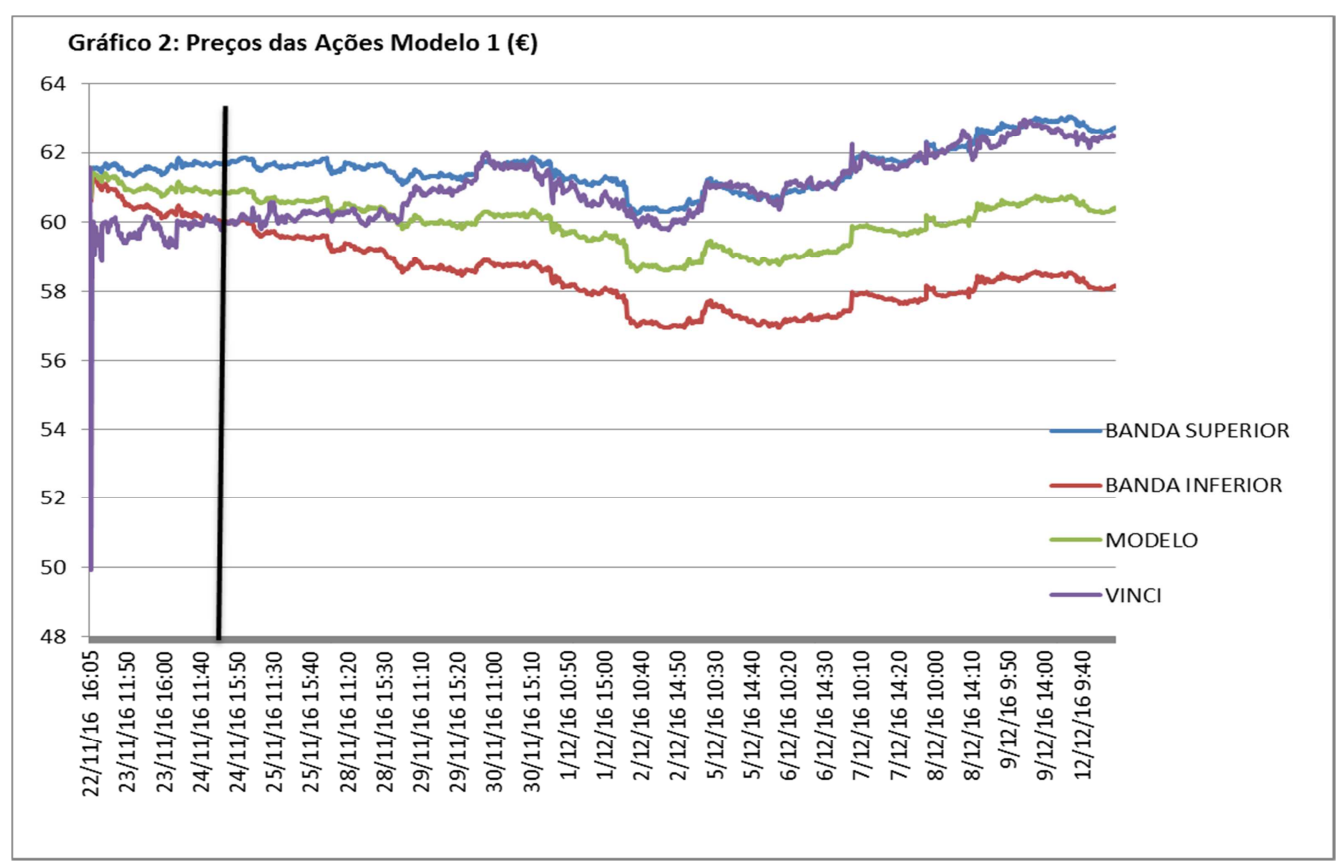




\section{1 .2 \\ Modelo (2)}

Considerando o contrafactual estimado a partir de fatores de Fama e French, verificamos que o modelo descreve bem o movimento do preço da ação durante todo o período projetado, uma vez que o preço real do ativo parece coincidir com o centro do intervalo de confiança, ou seja, com o valor previsto pelo modelo, sendo este, de todos os modelos, o mais aderente à trajetória real da ação.

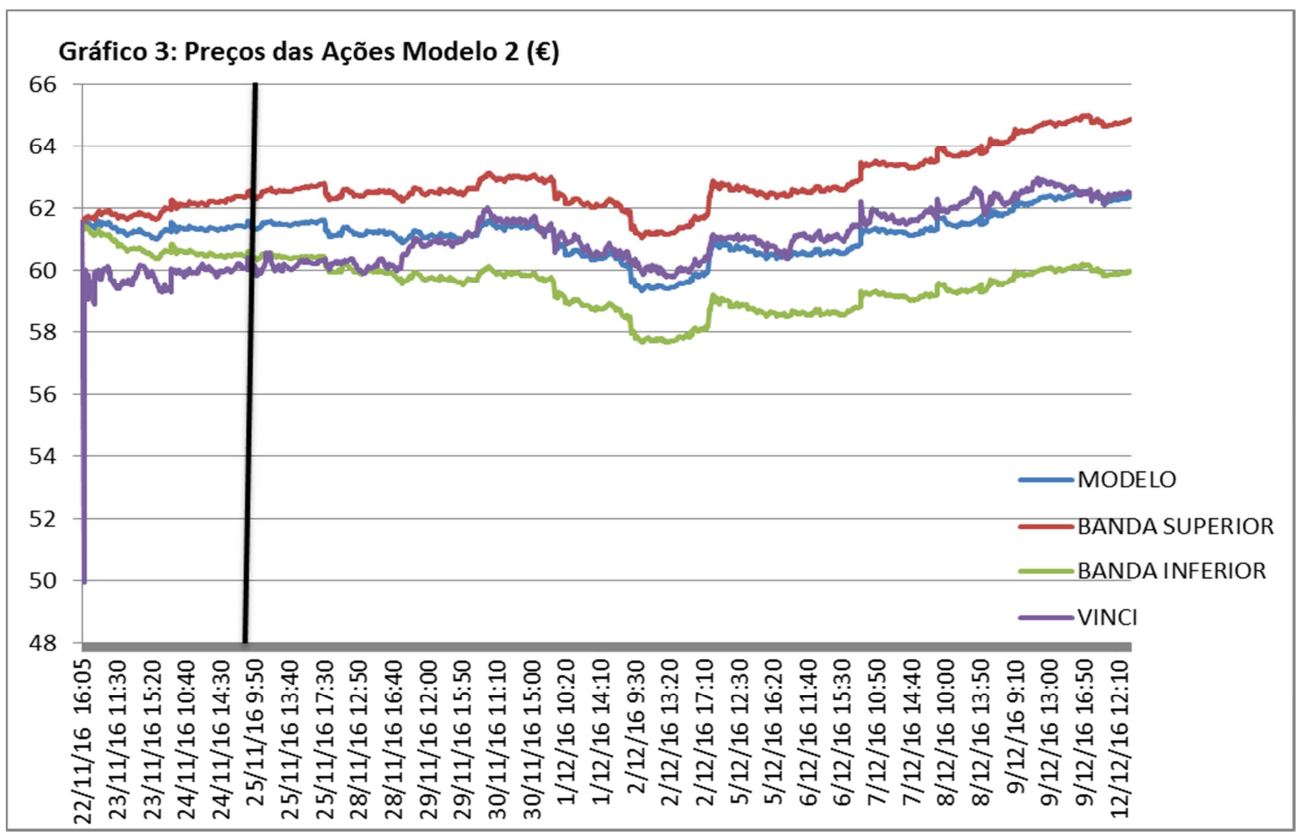

\subsection{3}

Modelo (3)

Considerando o contrafactual estimado a partir de fatores de Fama e French e da construção civil, verificamos que, tal como o modelo (1), o modelo (3) descreve bem o movimento do preço da ação no início do período projetado, após o qual parece subestimar a trajetória. Tal fato, porém, também não impacta a conclusão do modelo de que parece haver rigidez na volta do valor da ação da Vinci ao seu valor fundamental pelas mesmas razões do modelo 1. 


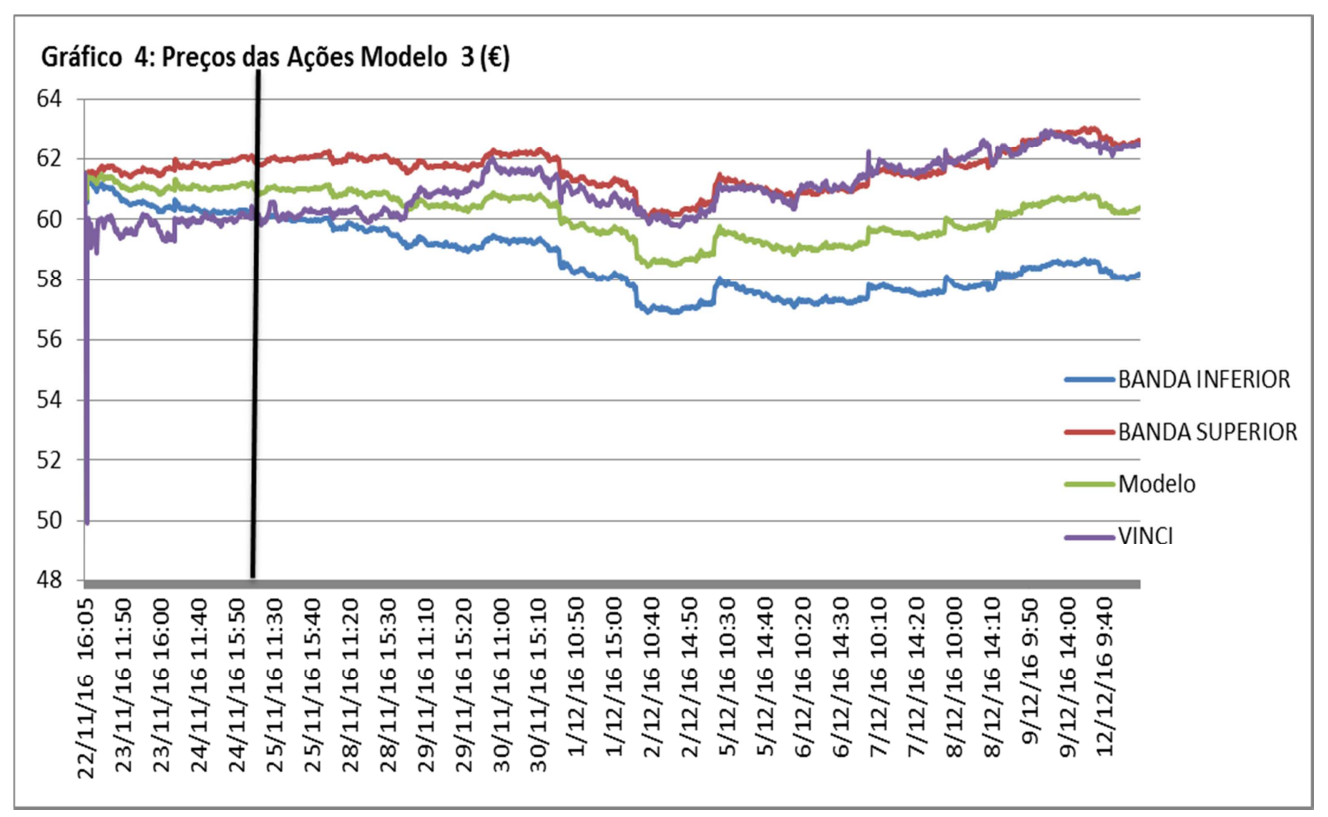

Conforme se pode observar, os três modelos, todos com considerável capacidade explicativa, evidenciam um efeito de rigidez na dissipação do choque provocado pela notícia falsa sobre o preço das ações da Vinci S.A. Esta persistência é consistente com os resultados de Carvalho et al (2011). sobre os efeitos do emblemático caso do choque de notícia falsa sobre as ações da United Airlines. Neste caso, os autores encontraram evidencias de rigidez dos preços mesmo utilizando um intervalo de confiança que considerava dois erros padrão, dada a magnitude do choque.

\section{2}

\section{Teste Placebo}

Com o objetivo de observar a validade do modelo para outras empresas da construção civil, nesta seção, o presente tralhado realizará um teste placebo para avaliar a aderência dos modelos propostos a outros ativos, verificando se eles estimam adequadamente o preço das ações de outras empresas da construção civil além da Vinci ou se captam algum tipo de contágio do choque da Vinci para outros players do setor.

Para realizar o teste, foram escolhidos papéis de outra empresa do setor de construção e materiais com ações transacionadas na bolsa de Paris: a Bouygues S.A. e aplicados os mesmos modelos que foram construídos para analisar o caso da Vinci, conforme as equações e os resultados a seguir, em que $r_{B, t}$ é o retorno 
logarítmico das ações da Bouygues transacionadas na Bolsa de Paris retirados da Thompson Reuters, com frequência de 5 minutos.

\begin{tabular}{|c|c|}
\hline \multicolumn{2}{|c|}{ Tabela 4: Resumo dos Resultados do Modelo 1 Bouygues } \\
\hline Parâmetros & Estimativas \\
\hline$\widehat{\alpha}$ & $\begin{array}{c}1,98 \mathrm{E}-05 \\
(0,39)\end{array}$ \\
\hline$\widehat{\beta}_{M}$ & $\begin{array}{c}4,37 E-01 \\
(0,00)\end{array}$ \\
\hline$\tilde{\beta}_{C V}$ & $\begin{array}{c}5,50 \mathrm{E}-01 \\
(0,00)\end{array}$ \\
\hline$R^{2}$ & 0,34 \\
\hline$\#$ Obs & 2.950 \\
\hline$\hat{\sigma}_{\theta}$ & $1,26 \mathrm{E}-03$ \\
\hline
\end{tabular}

(2) $\left(r_{B, t}-r_{t}\right)=\alpha+\beta_{M}\left(\mathrm{r}_{M, t}-r_{t}\right)+\beta_{S M B}\left(r_{S, t}-r_{B, t}\right)+\beta_{H M L}\left(r_{H, t}-r_{L, t}\right)$

Tabela 5: Resumo dos Resultados do Modelo 2 Bouygues

\begin{tabular}{cc}
\hline Parâmetros & Estimativas \\
\hline \hline$\alpha$ & $3,01 \mathrm{E}-05$ \\
& $(0,19)$ \\
$\widehat{\beta}_{M}$ & 1,01 \\
& {$[0,00]$} \\
$\hat{\beta}_{S M B}$ & $3,01 \mathrm{E}-05$ \\
$\widehat{\beta}_{H M L}$ & $(0,00)$ \\
& 0,66 \\
$\mathrm{R}^{2}$ & $(0,01]$ \\
$\#$ Obs & 0,33 \\
$\hat{\sigma}_{\theta}$ & 2.950 \\
\hline \hline
\end{tabular}


(3) $\left(r_{B, t}-r_{t}\right)$

$$
\begin{aligned}
& =\alpha+\beta_{M}\left(r_{M, t}-r_{t}\right)+\beta_{S M B}\left(r_{S, t}-r_{B, t}\right)+\beta_{H M L}\left(r_{H, t}-r_{L, t}\right) \\
& +\beta_{C V}\left(r_{C V, t}-r_{t}\right)
\end{aligned}
$$

\section{Tabela 6: Resumo dos Resultados do Modelo 3 Bouygues}

\begin{tabular}{cc}
\hline Parâmetros & Estimativas \\
\hline \hline$\alpha$ & $2,14 \mathrm{E}-05$ \\
$\widehat{\beta}_{M}$ & {$[0,35)$} \\
& $5,82 \mathrm{E}-01$ \\
$\widehat{\beta}_{C V}$ & $(0,00)$ \\
& $5,20 \mathrm{E}-01$ \\
$\widehat{\beta}_{S M B}$ & {$[0,00)$} \\
& $5,78 \mathrm{E}-01$ \\
$\widehat{\beta}_{H M L}$ & {$[0,00)$} \\
$\mathrm{R}^{2}$ & $1,62 \mathrm{E}-01$ \\
$\#$ Obs & {$[0,00)$} \\
$\hat{\sigma}_{e}$ & 0,36 \\
\hline \hline
\end{tabular}

Os modelos contrafactuais estimados para a Bouygues apresentam RQuadrado adequado e significância estatística para os coeficientes estimados, porém, os sinais para os coeficientes das variáveis explicativas nem sempre são os esperados, sobretudo em se tratando dos sinais dos coeficientes de Fama e French, que têm resultado positivo, apesar de o resultado esperado ser negativo, já que a Bouygues é uma grande empresa, com um valor de mercado considerável. A seguir, são apresentadas graficamente as estimativas contrafactuais resultantes dos modelos (1), (2) e (3) para os preços das ações da Bouygues em um período de 20 dias após o choque de notícia falsa em análise. 

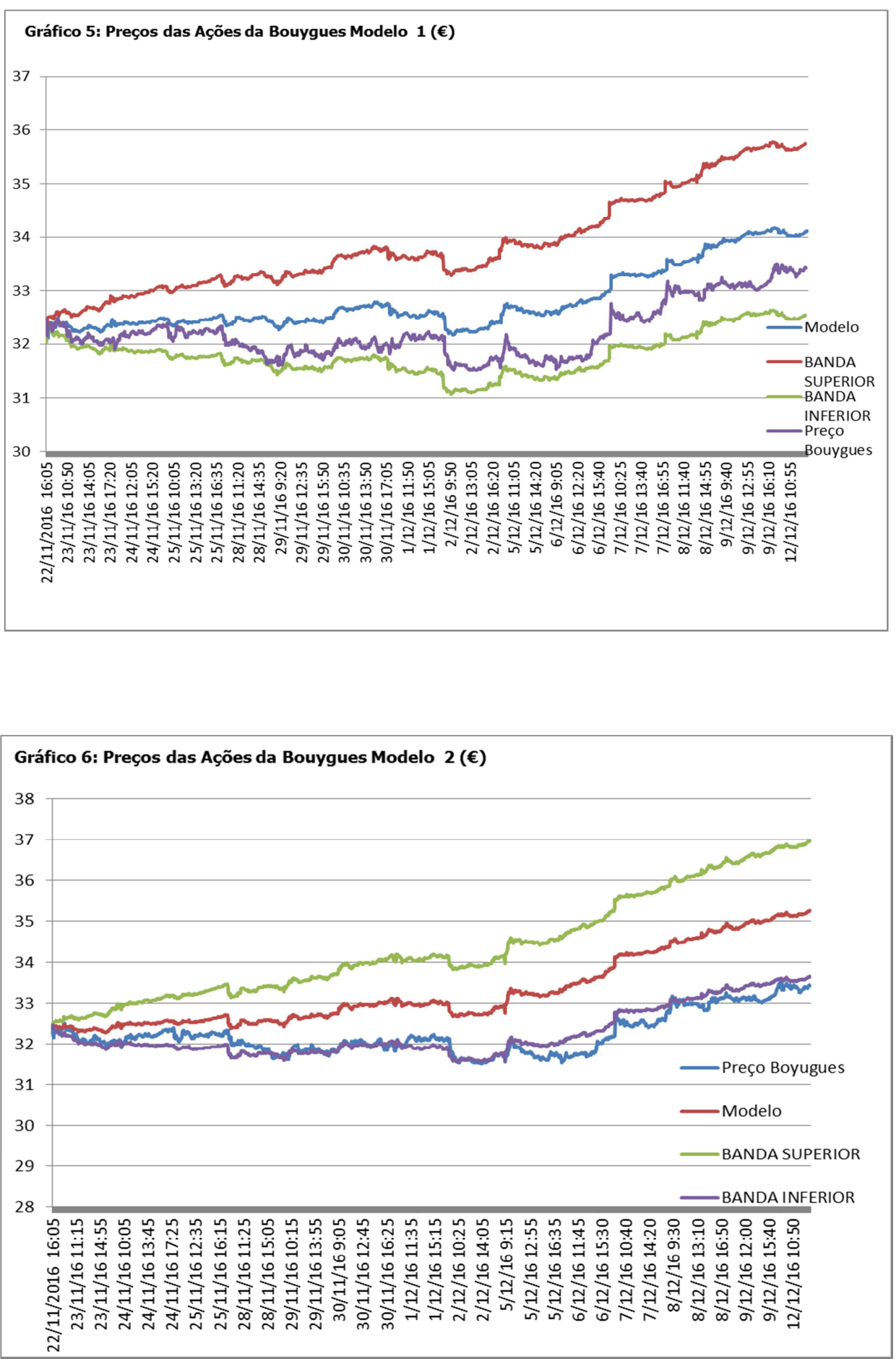


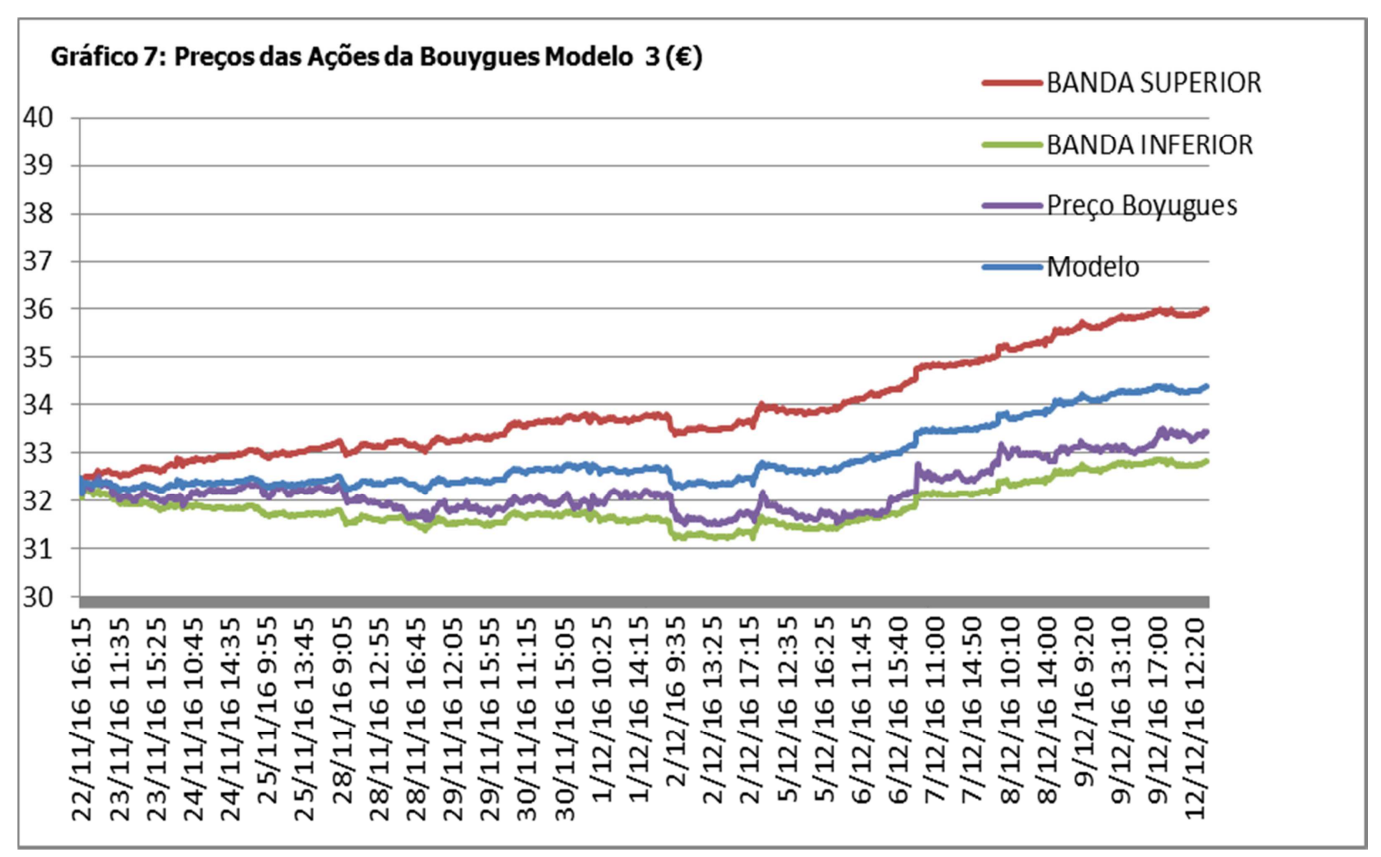

Os modelos contrafactuais não apontaram para a ocorrência de qualquer efeito contágio do choque de notícia falsa sobre as ações da Bouygues, indicando que os efeitos do choque ficaram limitados à Vinci. Todos os modelos superestimaram os preços das ações da Bouygues, porém, enquanto o modelo (1) e o (3) parecem estimar adequadamente estes preços, já que estes permanecem dentro das bandas de desvio padrão, no modelo (2), os preços verdadeiros das ações da Bouygues ficam consistentemente abaixo da banda inferior do modelo a partir de 5/12/2016.

\section{3}

\section{Teste de Robustez - Modelo de Frequência Diária}

Com o objetivo de testar a robustez do modelo, além dos testes placebo, foram construídos modelos idênticos ao Modelo (1), ao Modelo (2) e ao Modelo (3) baseados em dados com frequência diária, retirados da Reuters (desde 24/11/2015), para verificar se os sinais e o poder explicativo observado nos modelos de alta frequência se mantém caso o experimento seja realizado com dados de baixa frequência.

Os três modelos revelaram forte poder explicativo, com R-Quadrado em torno de 0,6. Além disso, apontaram no mesmo sentido do modelo de alta frequência quanto à persistência: nos modelos, os preços levam de dois a três dias 
para voltarem para as bandas de desvio-padrão, sugerindo que há uma rigidez temporária do choque de ruído. O modelo parece estimar adequadamente os preços das ações após a dissipação do choque: os preços dos modelos ficam próximos dos preços reais até o fim da projeção. Porém, o modelo em frequência diária não apresenta os mesmos sinais do modelo de alta frequência: os sinais estimados para os coeficientes do Fator de Fama French que captam a diferença entre os retornos de empresas de baixo valor e de alto valor de mercado deveriam ser negativos, já que a Vinci é uma Compahia de elevado valor de mercado. Porém, tanto no Modelo (1) quando no Modelo (2) de dados em baixa frequência, os coeficientes são positivos, prejudicando a robustez do modelo. A seguir, as estimativas e as projeções de cada modelo diário:

\subsection{1}

Modelo (1) - diário

Tabela 7: Resumo dos Resultados do Modelo 1 Vinci (diário)

\begin{tabular}{cc}
\hline \hline Parâmetros & Estimativas \\
\hline \hline$\alpha$ & $4,60 \mathrm{E}-05$ \\
$\widehat{\beta}_{M}$ & $(0,93)$ \\
& $4,83 \mathrm{E}-01$ \\
$\widehat{\beta}_{C V}$ & {$[0,00)$} \\
& $3,75 \mathrm{E}-01$ \\
$\mathrm{R}^{2}$ & $(0,00)$ \\
$\#$ Obs & 0,600 \\
$\hat{\sigma}_{\theta}$ & 256 \\
\hline \hline
\end{tabular}




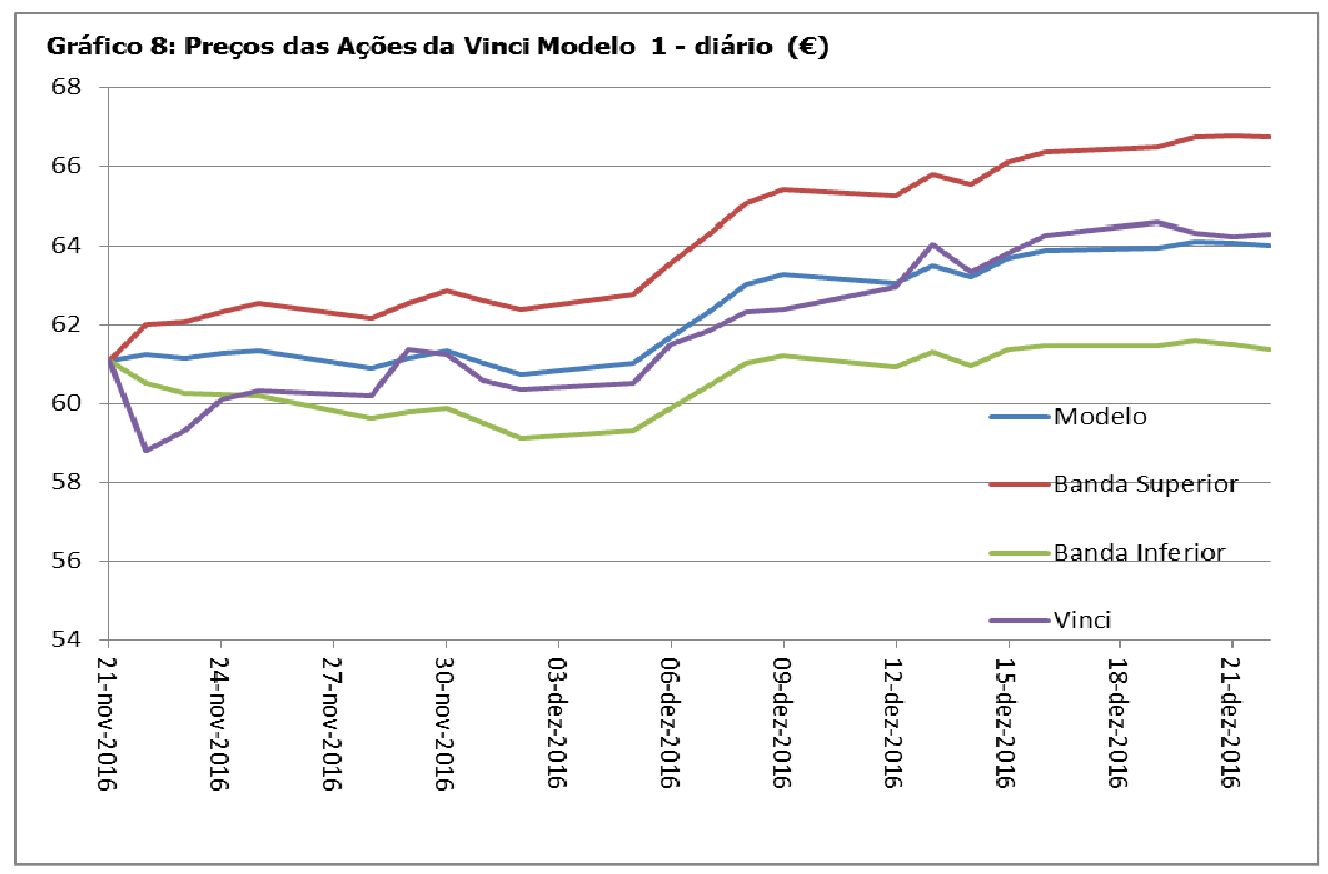

\subsection{2}

Modelo (2) - diário

Tabela 8: Resumo dos Resultados do Modelo 2 Vinci (diário)

\begin{tabular}{cc}
\hline \hline Parâmetros & Estimativas \\
\hline \hline$\widehat{\alpha}$ & $2,23 \mathrm{E}-04$ \\
$\widehat{\beta}_{M}$ & $(0,67)$ \\
$\widehat{\beta}_{S M B}$ & 0,85 \\
$\widehat{\beta}_{H M L}$ & $(0,00)$ \\
& $2,51 \mathrm{E}-01$ \\
$\mathrm{R}^{2}$ & {$[0,06]$} \\
$\#$ Obs & $-0,37$ \\
$\hat{\sigma}_{\theta}$ & $(0,00)$ \\
\hline \hline
\end{tabular}




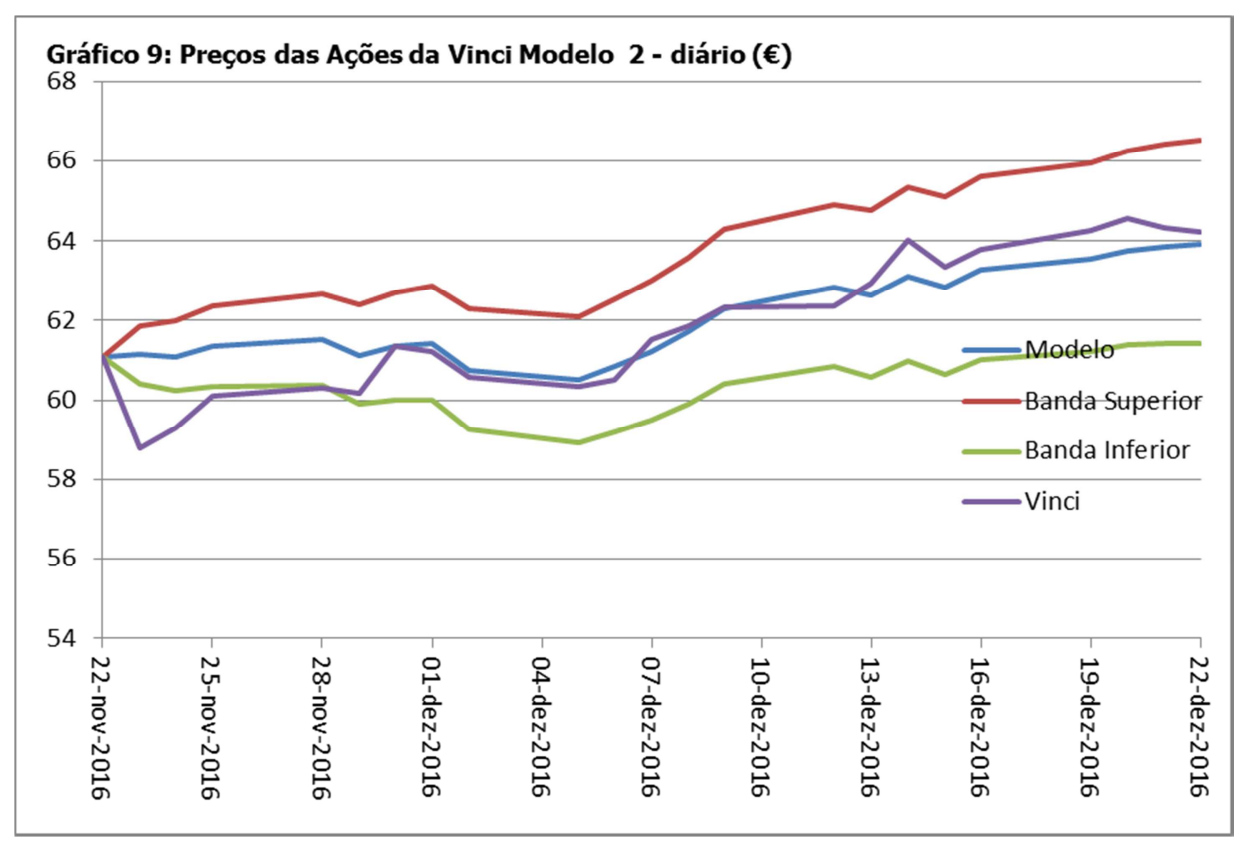

\subsection{3}

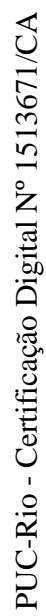

\section{Modelo (3) - diário}

Tabela 9: Resumo dos Resultados do Modelo 3 Vinci (diário)

\begin{tabular}{cc}
\hline \hline Parâmetros & Estimativas \\
\hline \hline$\alpha$ & $1,16 \mathrm{E}-04$ \\
$\widehat{\beta}_{M}$ & $(0,82)$ \\
$\widehat{\beta}_{C V}$ & $6,39 \mathrm{E}-01$ \\
& $(0,00)$ \\
$\widehat{\beta}_{S M B}$ & $2,80 \mathrm{E}-01$ \\
& $(0,01)$ \\
$\widehat{\beta}_{H M L}$ & $1,67 \mathrm{E}-01$ \\
$\mathrm{R}^{2}$ & $(0,21)$ \\
$\#$ Obs & $-3,39 \mathrm{E}-01$ \\
$\hat{\sigma}_{\theta}$ & {$[0,00)$} \\
& 0,62 \\
\hline \hline
\end{tabular}




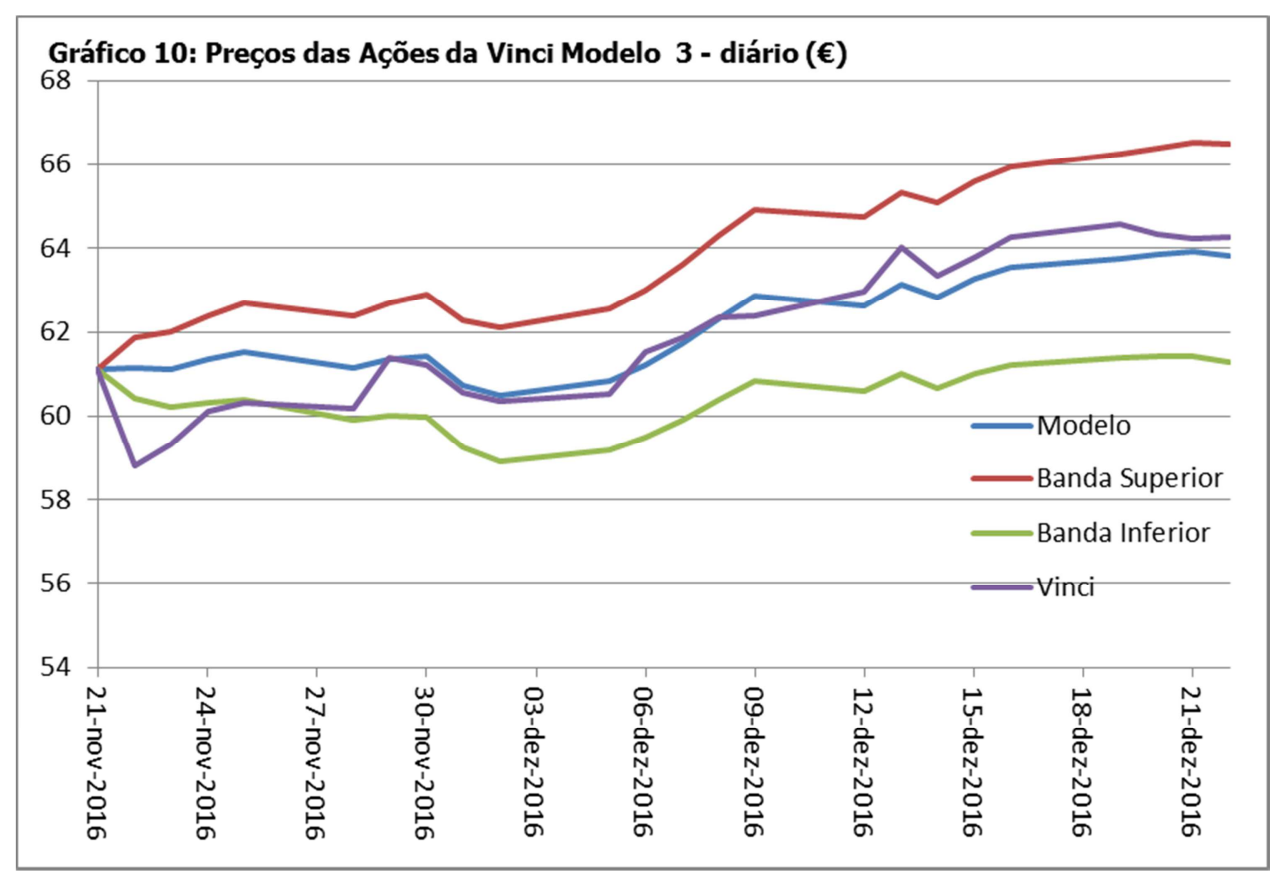

\section{4 Buscando uma alternativa para o Índice de Construção Civil - Frequência Diária}

Algumas das falhas apresentadas pelos modelos aqui propostos, como por exemplo, falhas específicas dos modelos que possuem o índice da construção civil como variável explicativa, que parecem subestimar os preços das ações da Vinci, podem ter origem em um problema de má especificação de variáveis.

O índice da construção civil Stoxx Global 1800 Construction and Materials EUR Price Index é um índice setorial global e não apenas europeu. A utilização de um índice global mostrou-se mais adequada do que a utilização de índices para a Europa devido ao elevado peso da Vinci na composição, porém, mesmo o índice global possui forte participação da Vinci na composição.

Para testar a melhor aderência de um índice regional da construção civil no modelo sem incorrer em endogeneidade, pode-se expurgar o componente endógeno e ao mesmo tempo retirar o "componente global” do Stoxx Global 1800 Construction and Materials EUR Price Index regredindo-o na diferença entre o índice de mercado global Stoxx Global 1800 EUR Price Index e o índice de mercado regional EuroStoxx Index e, em seguida, utilizando o resíduo desta regressão, já expurgado dos efeitos do mercado global sobre a construção civil e 
da endogeneidade, como índice regional com retorno $r_{C V e, t}$, conforme os Modelos (5) e (6) a seguir:

$$
\text { (5) }\left(r_{V, t}-r_{t}\right)=\alpha+\beta_{M}\left(\mathrm{r}_{M, t}-r_{t}\right)+\beta_{C V e}\left(r_{C V e, t}-r_{t}\right)
$$

(6) $\left(r_{V, t}-r_{t}\right)$

$$
\begin{aligned}
& =\alpha+\beta_{M}\left(r_{M, t}-r_{t}\right)+\beta_{S M B}\left(r_{S, t}-r_{B, t}\right)+\beta_{H M L}\left(r_{H, t}-r_{L, t}\right) \\
& +\beta_{C V e}\left(r_{C V e, t}-r_{t}\right)
\end{aligned}
$$

Onde, $\mathrm{r}_{G M, t}$ é um índice gobal de mercado, Stoxx Global 1800 EUR Price Index, e o $\mathrm{r}_{M, t}$ é o índice de mercado europeu, EuroStoxx Index. E $r_{C V e, t}$ é o resíduo da regressão a seguir, que representa um índice livre de endogeneidade:

$$
r_{C V, t}=\alpha+\beta_{R}\left(\mathrm{r}_{G M, t}-\mathrm{r}_{M, t}\right)
$$

Note-se que, pela análise dos resultados, pode-se verificar que o modelo perde em poder explicativo, apresentado um R-Quadrado bastante inferior na comparação com os modelos anteriores. A redução do R-Quadrado pode indicar o mercado global como uma variável importante para explicar o preço das ações da Vinci, já que o Grupo possui diversos investimentos fora da Europa. Ademais, enquanto o Modelo (5) apresenta os sinais esperados para os coeficientes, o Modelo (6) tem o sinal invertido para o coeficiente Small Minus Big. Ademais,

\begin{tabular}{|c|c|}
\hline Parâmetros & Estimativas \\
\hline$\widehat{\alpha}$ & $\begin{array}{c}1,80 \mathrm{E}-04 \\
(0,81)\end{array}$ \\
\hline$\widehat{\beta}_{M}$ & $\begin{array}{c}7,80 \mathrm{E}-04 \\
(0,00)\end{array}$ \\
\hline$\widehat{\beta}_{C V}$ & $\begin{array}{c}6,92 \mathrm{E}-01 \\
{[0,59)}\end{array}$ \\
\hline $\begin{array}{c}\mathrm{R}^{2} \\
\# \text { Obs } \\
\hat{\sigma}_{\theta}\end{array}$ & $\begin{array}{c}0,26 \\
256 \\
1,16 \mathrm{E}-02\end{array}$ \\
\hline
\end{tabular}
graficamente, os modelos parecem corroborar a conclusão dos Modelos (1), (2) e (3), apontando para uma rigidez temporária do choque de notícia falsa sobre os preços das ações da Vinci. 


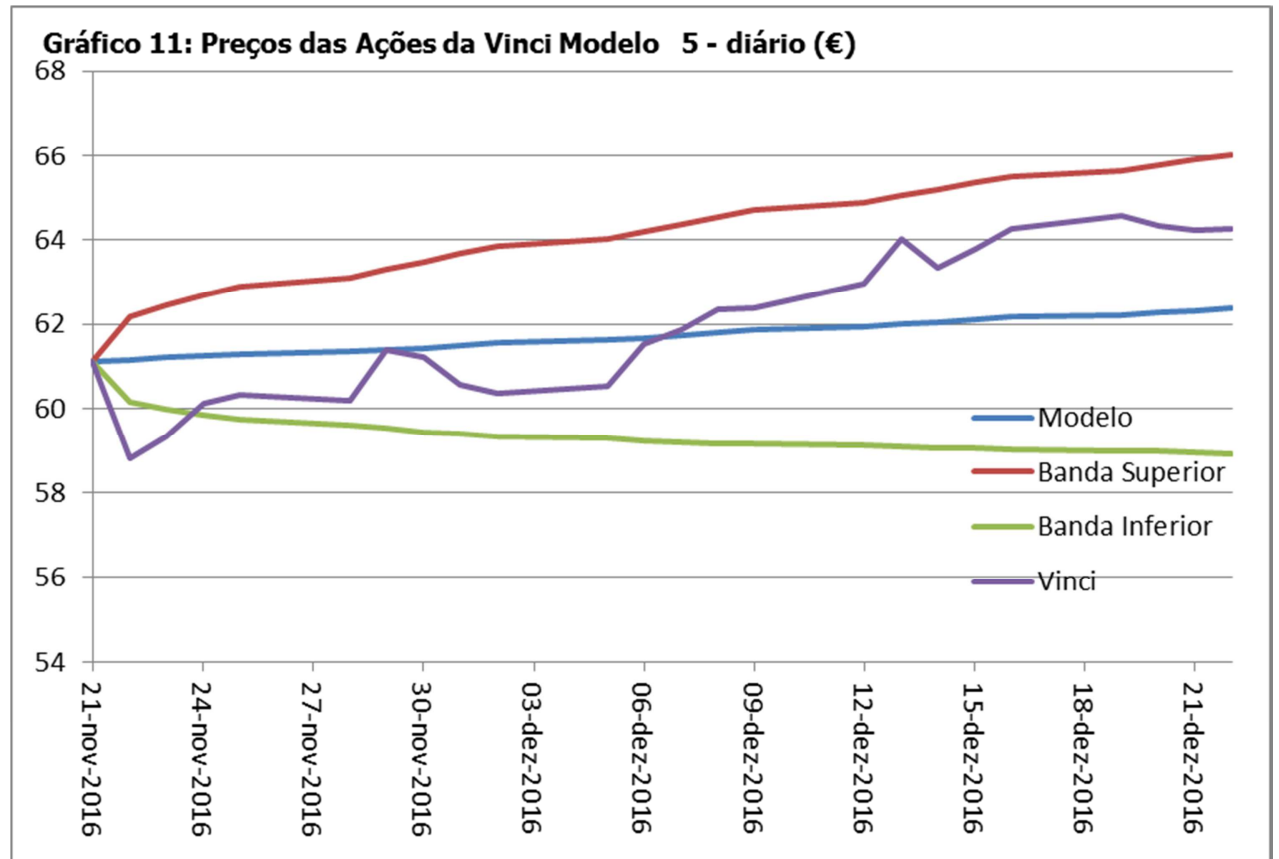

Tabela 11: Resumo dos Resultados do Modelo 6 Vinci

\begin{tabular}{ccc}
\hline \hline Parâmetros & & Estimativas \\
\hline \hline$\hat{\alpha}$ & & $1,85 \mathrm{E}-04$ \\
$\widehat{\beta}_{M}$ & & $(0,67)$ \\
& & $9,12 \mathrm{E}-04$ \\
$\hat{\beta}_{C V}$ & & $(0,00)$ \\
$\widehat{\beta}_{S M B}$ & & $6,59 \mathrm{E}-01$ \\
& & $(0,76)$ \\
$\widehat{\beta}_{H M L}$ & & $-3,45 \mathrm{E}-01$ \\
& & $(0,06)$ \\
$\mathrm{R}^{2}$ & & $(0,27 \mathrm{E}-01$ \\
$\#$ Obs & $\mathbf{V}$ & 0,27 \\
$\hat{\sigma}_{\theta}$ & & 256 \\
\hline \hline
\end{tabular}




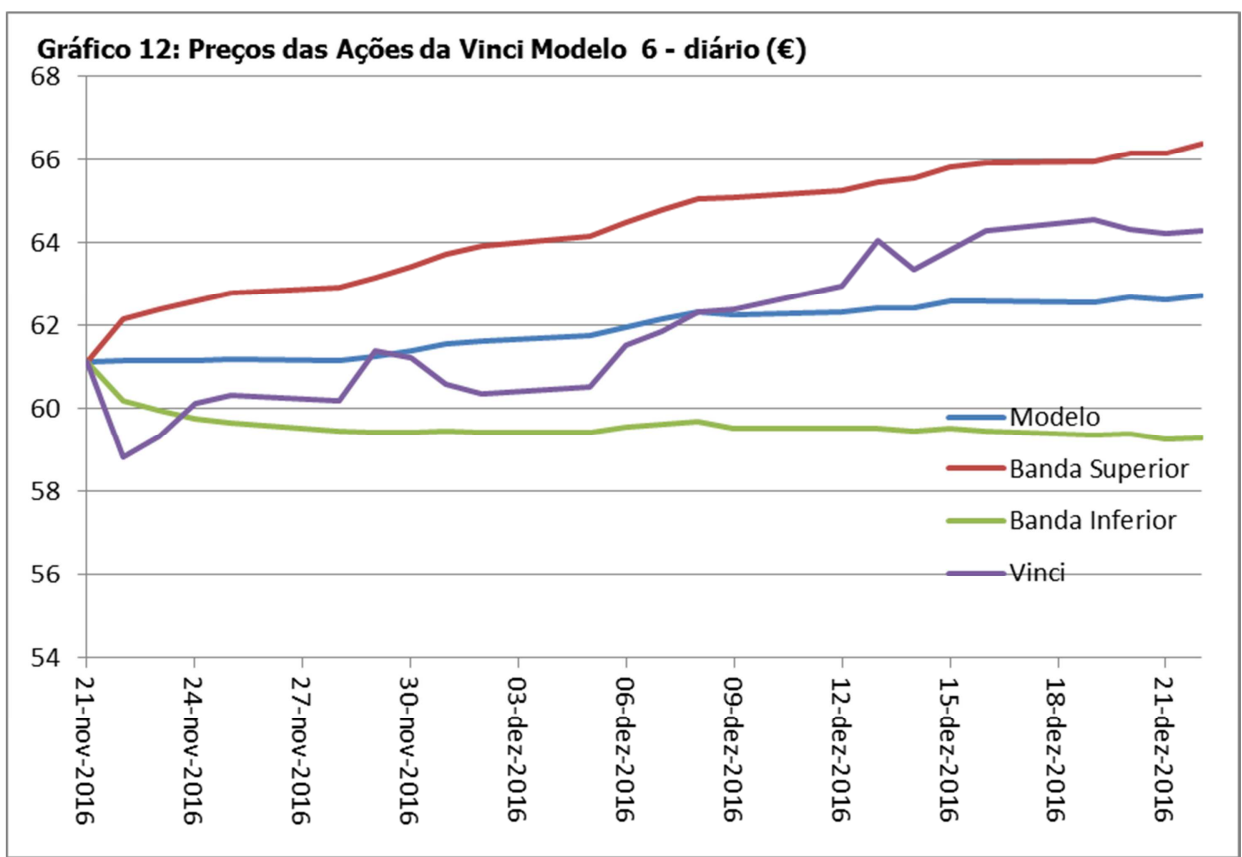

Uू 


\section{7 \\ Conclusão}

Este estudo buscou analisar se o choque de notícia falsa sobre as ações da Vinci teve algum componente de persistência. Os resultados aqui encontrados, apesar de alguns modelos subestimarem os preços das ações da Vinci, apontam para uma rigidez temporária na trajetória do preço das ações ao seu preço fundamental, tal como projetado pelos contrafactuais, o que contraria a hipótese da incorporação imediata da informação ao preço proposta por algumas teorias de mercados eficientes. Os modelos aqui propostos mostraram-se bem especificados e as suas conclusões se corroboram, apontando no mesmo sentido e conferindo robustez ao resultado, embora nenhum dos modelos tenha tido sucesso em incluir uma variável explicativa exógena como fizeram Carvalho et al. (2011), ao incluírem o preço do petróleo ao seu experimento, e os testes placebo e de robustez em baixa frequência não tenham sido conclusivos.

Além do caso da Vinci, o presente estudo apontou outros dois casos na literatura em que se verificou choques persistentes de notícia falsa: o caso da United Airlines, analisado por Carvalho et al. (2011) e o caso da Entre Med's, analisado por Huberman e Regev (2001). Apesar da evidência do caso a caso apontar para uma rigidez das respostas aos choques, não há uma quantidade suficiente de casos que confirme uma tendência clara generalizável.

A principal dificuldade da análise está na própria ocorrência rara dos casos, o que impede a construção de uma amostra ampla. O segundo problema está na construção de um contrafactual robusto e na dificuldade de se encontrar ativos e/ou índices para construir este contrafactual.

De 2012 a 2015, ocorreram pelo menos três tender offers falsas a empresas negociadas na New York Stock Exchange (NYSE) - bolsa de valores de Nova York, todas com efeito sobre os preços. Em maio de 2015, a empresa de cosméticos Avon Products foi vítima de uma notícia falsa relacionada a uma tender offer falsa submetida ao EDGAR, sistema da Securities and Exchange 
Commission (SEC) ${ }^{1}$, por uma empresa de private equity chamada PTG Partners Ltd., que apresentou uma proposta de compra de ações por US\$18,75, quase três vezes o valor de mercado naquela data. A oferta, realizada através de um sistema oficial, foi amplamente divulgada, levando as ações da Avon a uma subida que continuou mesmo após a deflagração de um circuit-break, levando o seu preço de US\$6,60 a quase US\$ 7,92, uma valorização de 20\%. Após a própria empresa declarar que a informação era falsa e que não havia recebido qualquer oferta de compra e dos analistas de mercado começarem a perceber que não havia sequer evidência de que a PTG Partners Ltd. existisse, o valor das ações recrudesceu, mas não totalmente, fechando o dia em US\$7,07, ou seja, com $7 \%$ de alta.

Nos anos anteriores, tender offers falsas já haviam sido feitas a empresas de porte menor do que a Avon, também com registro em sistemas oficiais, com impacto nos seus mercados de ações. Em 2012, foi a vez dos papéis da empresa Rocky Mountain Chocolate Factory e, em 2014, da empresa de seguros Tower Group terem picos em função de tender offers falsas.

O presente estudo buscou repetir o mesmo exercício realizado para as ações da Vinci, e de Carvalho et al. (2011) para a United, para os papéis da Avon, do Tower Group e da Rocky Mountain. Apesar de todos estes eventos configurarem amostras de choques de notícias falsas, o estudo não foi capaz de construir um contrafactual robusto, através de uma base de dados com índices do Center For Research in Securities Price (CRSP) e de fatores disponibilizados por Fama e French, sendo necessária a investigação de outros ativos e índices para a análise destes casos. Para os casos do Tower Group e da Rocky Mountain existe a dificuldade adicional da menor liquidez dos papéis em função de serem small caps.

Contudo, vale notar que tanto as ações da Avon quanto as da Tower e da Rocky Mountain tiveram altas razoavelmente duradouras após o choque de notícia falsa que sofreram, indicando que os três eventos configuram casos em que faz sentido construir um modelo para investigar se os choques de ruído tiveram mesmo rigidez na dissipação, tal como ocorreu com a Vinci e a United, ou se a duração das altas foi consequência de variações nos fundamentos.

\footnotetext{
${ }^{1}$ Órgão regulador do mercado de capitais dos EUA.
} 
8

\section{Referências bibliográficas}

ANDREW, W. Efficient Market Hypothesis. To appear in L. Blume and S. Durlauf, The New Palgrave: A Dictionary of Economics, Second Edition, 2007. New York: Palgrave McMillan.

BURTON, G. The Efficient Market Hypothesis and Its Critics, Princeton University, CEPS Working Paper № 91, 2003.

CARVALHO, C.; KLAGGE, N.; MOENCH, E. The Persistente Effects of a False News Shock. Journal of Empirical Finance, 18: 597-615, 2011.

DE LONG, J. Financial Markets, Noise Traders, and Fundamental Risk: Background, MEMO U.C. Berkeley and NBER, 2005.

DE LONG, J.; SHLEIFER, A.; SUMMERS, L.; WALDMANN, R. Noise Trader Risk in Finantial Markets. Chicago Journals, 98 (4): 703$738,1990$.

EPSTEIN, L.; SCHNEIDER, M. Ambiguity, Information Quality, and Asset Pricing. Journal of Finance, 63: 197-228, 2008.

[7] HUBERMAN, G.; REGEV, T. Contagious Speculation and a Cure for Cancer: A Non-Event that Made Stock Prices Soar. Journal of Finance, 56: 387-396, 2001.

LEI, A.; LI. H. Still in the Air: Who React to False Information? Dillard College of Business Administration Midwestern State University, 2010.

MARSHALL, B.; VISALTANACHOTI, N.; COOPER, G. Sell the Rumor, Buy the Fact?, 2010.

SCRUGGS, J. Noise Trader Risk: Evidence from the Siamese Twins. University of Georgia, Department of Banking and Finance, Terry College of Business, 2003.

SHLEIFER, A.; SUMMERS, L. The Noise Trader Approach to Finance. The Journal of Economic Perspectives, 4 (2): 19-33,1990.

TETLOCK P. All the News That.s Fit to Reprint: Do Investors React to Stale Information?. Yale University, 2008.

TETLOCK, P. Giving Content to Investor Sentiment: The Role of Media in the Stock Market. Journal of Finance, 62: 1139-1168, 2007. 
TETLOCK, P.; SAAR-TSECHANSKY, M.; MACSKASSY, S. More Than Words: Quantifying Language to Measure Firms Fundamentals. Journal of Finance 63: 1437-1467, 2008. 